\title{
DIREITO À CIDADE E PESSOAS COM DEFICIÊNCIA: O BEM-ESTAR URBANO COMO VETOR PARA A EFETIVAÇÃO DE DIREITOS
}

\author{
Rogério Luiz Nery da Silva ${ }^{1}$ \\ Darléa Carine Palma Mattiello
}

Resumo: A pesquisa insere-se no estudo da efetivação dos direitos sociais para as pessoas com deficiência, com recorte no direito à cidade, sustentabilidade e bem-estar urbano. $\mathrm{O}$ objetivo geral do trabalho é verificar os fatores determinantes para averiguar os critérios de efetivação dos direitos sociais às pessoas com deficiência nas cidades a partir da apuração do índice de bem-estar urbano. A pesquisa é bibliográfica e documental, com abordagem qualitativa e predominância do método dedutivo. Em conclusão, o trabalho aponta que parâmetros como mobilidade e infraestrutura são alicerces para a aferição da efetividade de direitos às pessoas com deficiência nas cidades.

Palavras-chave: Direitos fundamentais sociais; direito à cidade; sustentabilidade; bem-estar urbano; pessoa com deficiência.

\section{RIGHT TO THE CITY AND PEOPLE WITH DISABILITIES: URBAN WELL-BEING AS THE BASIS FOR THE REALIZATION OF RIGHTS}

\begin{abstract}
The research is part of the study of the realization of social rights for people with disabilities, focusing on the right to the city, sustainability and urban well-being. The general objective is to verify the determining factors to ascertain the criteria for the realization of social rights to people with disabilities in cities from the calculation of the urban well-being index. The research is bibliographic and documentary, with a qualitative approach and predominant deductive method. In conclusion, the paper points out that mobility and infrastructure are foundations for assessing the effectiveness of rights for people with disabilities in cities.
\end{abstract}

Key words: Fundamental social rights; right to the city; sustainability; urban well-being; disabled person.

\section{INTRODUÇÃO}

\footnotetext{
${ }^{1}$ Pós-doutor em Direitos Fundamentais e Ciência Política pela Université Paris-Nanterre Ecole doctorale de Sciences juridiques et politiques de Nanterre. Doutor em Direito Público e Evolução Social pela Universidade Estácio de Sá. Professor-doutor do Programa de Pós-Graduação em Direito stricto sensu da Universidade do Oeste de Santa Catarina (Unoesc). Advogado. Endereço postal: Av. Nereu Ramos, 3777-D, Seminário, Chapecó/SC, CEP 89813-000. Endereço eletrônico: dr.nerydasilva@ gmail.com. https://orcid.org/0000-00034317-5903 - http://lattes.cnpq.br/1275400369932551.

${ }^{2}$ Doutoranda e Mestre em Direitos Fundamentais pela Unoesc. Especialista em Direito Constitucional pela Unoesc. Professora na Graduação e Pós-Graduação lato sensu da Unoesc. Advogada. Endereço postal: Av. Nereu Ramos, 3777-D, Seminário, Chapecó/SC, CEP 89813-000. Endereço eletrônico: darlea.palma@ unoesc.edu.br. https://orcid.org/0000-0003-1342-4681 - http://lattes.cnpq.br/4357591928586392.
} 
A presente investigação tem por tema a efetivação de direitos sociais das pessoas com deficiência e toma por recorte os aspectos relativos ao direito à cidade, à sustentabilidade e ao bem-estar urbano. O problema de pesquisa reside em conferir se os fatores considerados de aferição do índice de bem-estar urbano são suficientes a garantir a efetividade de direitos sociais às pessoas com deficiência.

A justificativa para tal investida se deve ao fato de que as pessoas com deficiência encontram, sistematicamente, dificuldades de toda ordem no exercício e gozo de seus direitos mais elementares. No Brasil, porém, especialmente nas últimas décadas do século XX e primeiras décadas do século XXI, a produção normativa tem se dedicado a contemplar de forma mais abrangente essa preocupação, o que não é, contudo, uma garantia de resultado.

Nesse contexto, muitas vezes, é na "cidade", em sentido estrito, que as pessoas com deficiência têm maior possibilidade de identificar, por comparação, o grau e extensão das dificuldades que lhe acometem, já que, no meio urbano, as barreiras tanto físicas como sociais se fazem mais aparentes: o deslocamento, as condições de mobilidade, o acesso a construções edilícias e, até mesmo, a vias de circulação, dependendo da infraestrutura (in)existente, podem impedir as pessoas de alcançar seus objetivos, viver em condições de bem-estar e, por via de consequência, deixar de exercer os seus direitos, situações que facilmente se identificam pela mero contraste com a situação de vida das pessoas ditas "normais" que dividem o espaço com as pessoas com deficiência. Já no campo, a situação de isolamento pode conduzir a uma menor ou a uma ausência de percepção dessas terríveis restrições, e porque não dizer à certa resignação ou acomodação diante dessas injustas diferenças. O índice de bem-estar urbano é considerado globalmente e em duas vertentes específicas: a mobilidade e a infraestrutura urbana.

Como objetivo geral, a pesquisa buscará verificar, a partir das premissas teóricas, os fatores determinantes para averiguar os critérios de efetivação dos direitos sociais para as pessoas com deficiência no meio urbano a partir da apuração do índice de bem-estar urbano. Como objetivos específicos, têm-se: conhecer a base conceitual do direito à cidade; enfrentar a concepção conceitual de sustentabilidade e confrontá-las com os padrões de direitos sociais reconhecidos pela Constituição. Será também necessário identificar os indicativos dimensionais e numéricos de índice de bem-estar urbano em âmbito global e específico e analisar de forma crítica se tais índices são capazes de nortear e aferir a prestação de direitos às pessoas com deficiência no ambiente citadino. 
A fim de responder o problema proposto, adota-se a pesquisa bibliográfica e documental, com predominância do método dedutivo e abordagem qualitativa, mediante estudo da literatura técnica e doutrinária atinentes, das normativas aplicáveis à espécie e dos levantamentos de dados já produzidos. Com o mesmo intuito elucidativo, divide-se, estruturalmente, o trabalho em duas partes distintas: a primeira, denominada "Direitos sociais e o direito à cidade", voltada a apresentar premissas teóricas; e a segunda, identificada como "Pessoas com deficiência e o bem-estar urbano: a evidência dos números", destinada à análise dos dados, de forma vinculada às concepções doutrinárias e normativas.

\section{PESSOAS COM DEFICIÊNCIA E DIREITO À CIDADE: CONCRETIZAÇÃO DE DIREITOS POR MEIO DO BEM-ESTAR URBANO}

As pessoas com deficiência têm, em seu favor, uma série de previsões normativas que levam em conta as necessidades especiais que lhes são características. Porém, contar com a tutela normativa não assegura, por si só, que os direitos previstos serão efetivados. Dessa forma, impende-se estudar o contexto da efetivação de direitos para as pessoas com deficiência e, com especial cuidado, a prestação dos direitos sociais, no contexto das cidades, considerando-se o Índice de Bem-Estar Urbano (IBEU), compilado pelo Observatório das Metrópoles, a partir de dados levantados pelo Instituto Brasileiro de Geografia e Estatística (IBGE).

Vários direitos sociais previstos constitucionalmente são relacionados com o ambiente no qual se insere o seu titular ${ }^{3}$. Assim, nessa gama de possibilidades, não há como se desvincular o direito à cidade e, em concepção mais acurada, a uma cidade sustentável, como forma de contribuição para a efetividade dos consectários constitucionais. Por via de consequência, considerando-se que as condições de vida proporcionadas em um ambiente urbano adequado são imprescindíveis, sob vários aspectos, para a consolidação dos direitos às pessoas com deficiência, justifica-se a importância do presente estudo.

Invocam-se as premissas conceituais sobre a cidade apresentadas por Lefebvre (2001, p. 62), como sendo a "projeção da sociedade sobre um local", ou seja, não apenas sobre o lugar sensível como também sobre o plano específico, percebido e concebido pelo

\footnotetext{
${ }^{3}$ A Constituição da República Federativa do Brasil teve o texto de seu artigo $6^{\circ}$ modificado com a Emenda Constitucional n. 90, de 2015, para inserir o transporte dentre os direitos sociais, somando-se a educação, saúde, alimentação, trabalho, moradia, lazer, segurança, previdência social, proteção à maternidade e à infância, e assistência aos desamparados, já previstos constitucionalmente (BRASIL, 1988).
} 
pensamento, que determina a cidade e o urbano. Segundo o autor, para os filósofos e para a filosofia, a cidade não foi uma simples questão objetiva, um conceito sociológico ou um dado externo; os filósofos da filosofia clássica "pensaram a cidade, trouxeram a vida urbana para a linguagem e para o conceito" (LEFEBVRE, 2001, p. 35).

Em importante vinculação com o que se tem, atualmente, no Brasil, em termos de direitos sociais, Lefebvre (2001, p. 138-139) afirma que direitos mal reconhecidos "mudariam a realidade se entrassem para a prática social", referindo-se especificamente ao direito ao trabalho, à educação, à saúde, à habitação, aos lazeres, dentre outros. $\mathrm{O}$ autor insere o direito à cidade entre os citados, esclarecendo que se refere "não à cidade arcaica mas à vida urbana, à centralidade renovada, aos locais de encontros e de trocas, aos ritmos de vida e empregos do tempo que permitem o uso pleno e inteiro desses locais" (LEFEBVRE, 2001, p. 139).

\subsection{Direitos sociais e o direito à cidade}

Ao Estado compete prestar elementos condicionais aos cidadãos para que exerçam seu direitos e garantias, em virtude da demanda de prestações positivas a serem veiculadas e efetivamente implementadas por meio das políticas públicas. Nas cidades, verifica-se, sobremaneira, a necessidade da atuação estatal, seja para organizar os espaços urbanos ou para proporcionar meios aos cidadãos de (con)viver nesses locais com o bem-estar condizente a uma vida digna ${ }^{4}$, independentemente de suas condições pessoais.

Cabendo, portanto, ao Estado realizar as prestações que lhe são atribuídas legalmente ${ }^{5}$, os entes públicos devem fazê-lo de forma plena, cumprindo as determinações constitucionais. Até porque a função estatal de coordenar as ações para a realização de direitos dos cidadãos, segundo Bucci (1997, p. 90) legitima-se pelo convencimento da sociedade quanto à necessidade de realização de direitos, inclusive - e principalmente - dos direitos sociais, que possuem vértice prestacional.

Invoca-se, aqui, a consagrada concepção de Alexy (2015, p. 433-434), para quem algumas previsões normativas constituem o que é denominado "direito a prestações”, ou seja, os direitos a uma ação positiva do Estado, que pertencem a um status positivo, em sentido

\footnotetext{
${ }^{4}$ Haberle (2009, p. 81) afirma que a exata compreensão do que vem a ser o estado de direito depende da existência de um compromisso de sua Constituição com a dignidade humana.

${ }^{5}$ Considera-se, aqui, o conceito de "lei" lato sensu, da forma mais ampla e genérica possível, abrangendo toda e qualquer espécie normativa hábil a autorizar o agir do Estado, enquanto Administração Pública. É o que foi denominado por Freitas (2009, p. 70) de legalidade temperada, no sentido de que a Administração Pública deve pautar-se no Direito como "uma totalidade aberta, maior que o conjunto de regras legais", considerando-se que "o conteúdo jurídico, por força da natureza valorativa, transcende o mero e esparsamente positivado".
} 
estrito. Em contraponto, viriam os direitos de defesa do cidadão contra o Estado, constituindose direitos a ações negativas do Estado.

Na esteira dessa classificação, são as palavras de Sarlet (2012, p. 260), para quem os direitos fundamentais, em razão de sua multifuncionalidade, podem ser classificados basicamente em dois grandes grupos, nomeadamente os direitos de defesa e os direitos a prestações. Incluem-se, segundo o autor (SARLET, 2012, p. 260), no primeiro grupo os direitos de liberdade, igualdade, as garantias, bem como parte dos direitos sociais (no caso, as liberdades sociais) e políticos; o segundo grupo, por sua vez, integra-se pelos direitos a prestações em sentido amplo, incluindo os direitos sociais de natureza prestacional.

Nessa linha de raciocínio, considerando-se o espaço da cidade como um produto social, tem-se o direito à cidade como consectário lógico de um ideal da vida em sociedade, a fim de que, no ambiente urbano, possam os citadinos exercer, em sua plenitude, os direitos que são conferidos em determinado período histórico pelas respectivas previsões normativas.

O termo "direito à cidade" é atribuído a Henri Lefebvre, desenvolvido no livro de mesmo nome publicado em 1968 em francês ("Le Droit à la Ville") 6 . Segundo Lefebvre (2001), utiliza-se a expressão a partir do direito que as pessoas possuem de acesso à vida urbana, considerando-se a premissa que "o habitar reencontra seu lugar acima do habitat" (LEFEBVRE, 2001, p. 132).

Lefebvre (2001, p. 11) apresenta o processo de industrialização como ponto de partida para estudar o que designa de "problemática urbana", afirmando, porém, que a cidade é anterior à industrialização e que, ao longo da evolução urbanística, podem-se distinguir três períodos: a destruição da realidade urbana pela indústria; a ampliação da urbanização, descobrindo-se que a sociedade pode se decompor sem a cidade; e o reencontro ou reinvenção da sociedade urbana (LEFEBVRE, 2001, p. 28).

Ante a vinculação entre a cidade, o urbano e o campo, bem como da invenção de novas formas urbanas, Lefebvre (2001, p. 75) afirma ter havido uma acentuação da oposição "urbanidade-ruralidade" e uma atenuação da oposição "cidade-campo". Destaca, ainda, que "a extensão da cidade produz o subúrbio e depois o subúrbio engole o núcleo urbano", deslocando-se a problemática para o desenvolvimento urbano (LEFEBVRE, 2001, p. 83-85).

Ao abordar especificamente o direito à cidade, Lefebvre afirma que as necessidades sociais possuem fundamento antropológico e que se acrescentam necessidades urbanas

\footnotetext{
${ }^{6}$ O presente estudo utiliza a versão traduzida para o português por Rubens Eduardo Frias, publicada em 2011 pela Centauro Editora.
} 
específicas às necessidades antropológicas socialmente elaboradas. Consequentemente, não se poderia reconstituir uma cidade antiga, considerando-se, no contexto atual, apenas a criação de novas cidades, "sobre novas bases, numa outra escala, em outras condições numa outra sociedade" (LEFEBVRE, 2001, p. 105-106).

Tal concepção é corroborada por Harvey (2012, p. 73), ao afirmar que "se a cidade é o mundo que o homem criou, doravante ela é o mundo onde ele está condenado a viver”. E ainda, ao preceituar que as pessoas têm o direito de mudarem-se a si próprias pela mudança da cidade, pois a cidade que se deseja não pode ser divorciada dos laços sociais.

As cidades, por configurarem um espaço social e por necessitarem acompanhar os fatos sociais, possuem estreita relação com as noções de sustentabilidade ${ }^{7}$, constituindo campo propício para análise, ideias de concretização e desenvolvimento principiológico do que seria o "sustentável”. Bosselmann (2015, p. 25-29) esclarece que a sociedade humana aqui compreendida como espaço do convívio social das pessoas - e o ambiente natural mantiveram equilíbrio por dilatado tempo, o que nos remete à ideia de sustentabilidade, alertando, porém, para um eventual comprometimento do uso desse termo, não se podendo desvirtuar seu significado.

As afirmações de Bosselmann (2008, p. 25) são no sentido de que, com o desenvolvimento de seu conceito, a sustentabilidade já foi compreendida de diversas formas, a partir da Conferência das Nações Unidas para o Meio Ambiente Humano (CMAH) realizada em Estocolmo, em 1972, passando a ser vista, inclusive, como "desenvolvimento sustentável". ${ }^{8}$ Isso não significa, porém, que foi descartado o conceito de sustentabilidade originalmente idealizado (BOSSELMANN, 2008, p. 35).

Entende-se que, cada vez mais, as cidades devem se coadunar com o ideal de sustentabilidade em uma compreensão contemporânea de seu conceito. Nessa acepção, Freitas e Garcia (2018, 0. 22-23) defendem um conceito de sustentabilidade ao qual se adicionam as dimensões jurídica, política e ética, levando em conta a "relação dialética e circular do homem com o todo". Trata-se, portanto, de atrelar as noções de sustentabilidade a uma

\footnotetext{
${ }^{7}$ Não à toa, Freitas (2012) apresenta a sustentabilidade como um princípio e valor supremo do Estado Constitucional.

${ }^{8}$ São as seguintes as afirmações do autor (BOSSELMANN, 2008, p. 25): "Both advocates and critics of the concept of sustainable development agree that the original meaning of sustainability has been obscured by the Brundtland definition. They disagree, however, on whether or not sustainability has been replaced by sustainable development so that it is no longer relevant for policy and law-making."
} 
relação intersubjetiva, ultrapassando a correlação ontológica, biológica ou ecológica do homem e os recursos naturais.

Harvey (2014) declara que a ocupação do espaço público nunca foi tão discutida como neste início do século XXI, sobressaindo-se discussões sobre acesso aos recursos urbanos e a organização da vida cotidiana, com qualidade e igualdade. Até porque não se pode olvidar que que o desenvolvimento sustentável está relacionado com o progresso econômico (MEDEIROS, 2020, p. 141), no sentido de ambos caminharem conjuntamente, a fim de que a preservação da integridade do ecossistema não comprometa o avanço econômico necessário para o progresso, e vice-versa.

Registra-se, ainda, que o homem da sociedade urbana contemporânea possui novas precisões ${ }^{9}$. Assim, "o direito à cidade não pode ser concebido como um simples direito de visita ou de retorno às sociedades tradicionais" (LEFEBVRE, 2001, p. 117), impondo-se sua formulação como direito à vida urbana, transformada, renovada. A cidade, ainda que em novas condições, deve reunir "os interesses (aqueles que superam o imediato e o superficial) de toda a sociedade, e inicialmente de todos os que dela habitam", nos termos de Lefebvre (2001, p. 118).

Nesse ponto, a teoria de Lefebvre cruza-se com a análise das normativas destinadas às pessoas com deficiência, uma vez que, em se tratando de pessoas originalmente excluídas do contrato social $^{10}$, as pessoas com deficiência não são as destinatárias imediatas das políticas públicas urbanas gerais. Rolnik e Klink (2011), no mesmo condão argumentativo, transportam a discussão para o âmbito da exclusão e inclusão, apresentando a cidade como a representação de "uma arena privilegiada no processo de acumulação", situação na qual "os atores sociais tradicionalmente excluídos da sua função social não têm conseguido se apropriar devidamente dos frutos do crescimento econômico".

De qualquer forma, o espaço citadino merece atenção, ante a crescente urbanização verificada ao longo do século XX e a consequente necessidade de acomodar os diversos

\footnotetext{
${ }^{9}$ Estranhamente, segundo Lefebvre (2001, p. 117), "o direito à natureza (ao campo e à 'natureza pura') entrou para a prática social há alguns anos em favor dos lazeres", conduzindo-se uma comercialização que destrói, por si só, a naturalidade do campo. Daí surge o questionamento do autor: "o direito à natureza e o direito ao campo não se destroem a si mesmos"? (LEFEBVRE, 2011, p. 117).

${ }^{10}$ Ao se pensar as doutrinas do contrato social, sobressai-se a premissa rousseauniana sobre a vida social ser "considerada sobre a base de um contrato, em que cada contratante condiciona sua liberdade ao bem da comunidade, procurando proceder sempre de acordo com as aspirações da maioria" (ROUSSEAU, 2001, p. 8). As pessoas com impedimentos físicos e mentais não se incluem, em primeira análise, no grupo daqueles que escolhem os princípios políticos básicos (NUSSBAUM, 2013, p. 19), estabelecendo as regras do contrato social, daí a necessidade da inclusão observando-se as necessidades especiais de tais pessoas.
} 
grupos sociais que compõem a urbe. Ao contrário da maioria das pessoas ditas "normais", aquelas que possuem necessidades especiais para locomoção, habitação e outras atividades diárias nas cidades merecem especial atenção, no que tange às políticas públicas implementadas no espaço urbano e o bem-estar que, delas, pode resultar.

\subsection{Pessoas com deficiência e o bem-estar urbano: a evidência dos números}

No sentido de promoção da inclusão e de análise dos resultados das medidas promovidas, convém ressaltar as palavras de Alvino-Borba e Mata-Lima (2011, p. 222). Ao analisar a exclusão e a inclusão social nas sociedades modernas, afirmam que "exclusão social é um forte fator de preocupação da sociedade contemporânea e que, infelizmente, as políticas de inclusão não têm sido suficientes para fazer face aos imperativos sociais", o que se verifica primordialmente na organização dos espaços urbanos.

Nussbaum (2013, p. 2), no mesmo sentido, esclarece que um dos problemas pendentes de resolução na sociedade funda-se na justiça social para pessoas com impedimentos físicos e mentais. Ou seja, algumas capacidades são tão importantes para a vida humana que, em caso de falta de qualquer uma delas, não se configuraria uma vida humana com dignidade, o que inclui, por óbvio, a concretização de ações no ambiente urbano.

Propõe a autora (NUSSBAUM, 2013), assim, a aceitação das terminologias "impedimentos" e "deficiências" em suas diferentes concepções, frisando haver, pelo menos, duas maneiras de compreender a deficiência. A primeira a entende como uma manifestação da diversidade humana, entendendo-se que um corpo com impedimentos é o de alguém que vivencia impedimentos de ordem física, intelectual ou sensorial ${ }^{11}$ (essa ideia correspondente ao modelo social da deficiência, por meio do qual a garantia da igualdade entre pessoas com e sem impedimentos corporais não deve se resumir a critérios biomédicos). Já a segunda forma de entender a deficiência sustenta que ela é uma desvantagem natural, devendo os esforços se concentrarem em reparar os impedimentos corporais, a fim de garantir a todas as pessoas um padrão de funcionamento típico à espécie.

O deslocamento do tema da deficiência dos espaços domésticos para a vida pública foi permitido e consolidado pela tese central do modelo social, até porque a deficiência não é matéria de vida privada ou de cuidados familiares, mas uma questão de justiça, segundo

\footnotetext{
${ }^{11}$ Nessa análise, não se pode afastar a ideia de que as barreiras sociais, ao ignorar os corpos com impedimentos, provocam a experiência da desigualdade, sendo a opressão não um atributo dos impedimentos corporais, mas resultado de sociedades não inclusivas (NUSSBAUM, 2013).
} 
Nussbaum (2013). Com isso, a inclusão social recebeu outra concepção, constituindo-se como um processo bilateral pelo qual "a sociedade se adapta para poder incluir, em seus sistemas sociais gerais, pessoas com deficiência (além de outras) e, simultaneamente, estas se preparam para assumir seus papeis na sociedade" (SASSAKI, 2010, p. 39).

Distinguem-se, assim, os conceitos de "impedimento" (impairment), "deficiência" (disability) e "incapacidade" (handicap) ${ }^{12}$, impondo-se que as pessoas, ainda excluídas, e a sociedade busquem equacionar problemas em parceria, ao mesmo tempo em que decidem sobre soluções e efetivam a equiparação de oportunidades para todos.

A separação entre o normal e o patológico, representada pela oposição entre o corpo sem e com impedimentos, permitiu a consolidação do combate à discriminação como objeto de intervenção política, tal como previsto pela Convenção das Nações Unidas sobre os Direitos das Pessoas com Deficiência (BRASIL, 2009), ratificada pelo Brasil em 2008 e promulgada no Brasil em 2009 pelo Decreto n. 6.949 ${ }^{13}$. Como resultado das discussões internacionais entre os modelos biomédico e social, referido instrumento define as pessoas com deficiência como "aquelas que têm impedimentos de natureza física, intelectual ou sensorial, os quais, em interação com diversas barreiras, podem obstruir sua participação plena e efetiva na sociedade com as demais pessoas" (BRASIL, 2009).

A Convenção da ONU, assim, enfatiza a perspectiva de que se deve reconhecer a deficiência como um "conceito em evolução", segundo seu preâmbulo. Impõe-se, assim, olhar a deficiência como resultado de uma interação, propiciada em maior ou menor grau, das pessoas com impedimentos e obstáculos, sejam ambientais ou comportamentais (BRASIL, 2009). Significa dizer que a deficiência somente será assim considerada se impedir a inclusão plena e a efetiva participação das pessoas na sociedade com fulcro nas oportunidades com os demais, se estas não forem iguais.

A partir dessas considerações, torna-se imperativo analisar a concretização dos direitos previstos para as pessoas com deficiência no ambiente urbano, considerando-se que

\footnotetext{
${ }^{12}$ Segundo a abordagem de Sassaki (2010, p. 45-46), esses conceitos são assim diferenciados segundo a Organização Mundial de Saúde (OMS): impedimento, como sendo "qualquer perda ou anormalidade da função ou estrutura psicológica, fisiológica ou anatômica"; deficiência, "qualquer restrição ou falta (resultante de um impedimento) da habilidade para desempenhar uma atividade de uma maneira, ou com variância, considerada normal para um ser humano"; e incapacidade, "uma desvantagem, resultante de um impedimento ou de uma deficiência, que limita ou impede a realização de um papel considerado normal para um dado indivíduo", considerando-se, aí, as variáveis de idade, sexo e fatores sociais e culturais.

${ }^{13}$ Conferiu-se patamar relevante à Convenção da ONU sobre as Pessoas com Deficiência, tendo sido esse o primeiro diploma internacional a ser aprovado no Brasil com status de Emenda Constitucional, nos termos do parágrafo $3^{\circ}$ do artigo $5^{\circ}$ da Constituição da República Federativa do Brasil de 1988.
} 
eventuais impedimentos e deficiências permitem constatação direta no ambiente diário, conforme os fatores socioambientais que interferem no agir em sociedade. Assim, importa ao presente estudo conhecer o número de pessoas com deficiência e da população urbana no Brasil, bem como, nesse cenário, quais as condições de bem-estar urbano ofertadas às pessoas com deficiência. Para tanto, são utilizados os dados colhidos no último censo decenal do Instituto Brasileiro de Geografia e Estatística (IBGE), em 2010.

Dados desse censo - para o qual 191 mil recenseadores visitaram 67,6 milhões de domicílios nos 5.565 municípios brasileiros - apontaram uma população formada por quase 191 milhões de pessoas. O censo procurou identificar o número de pessoas com deficiências visual, auditiva e motora, considerando os graus de severidade das deficiências, e a deficiência mental ou intelectual. Os resultados apontaram que quase 46 milhões de pessoas declararam ter pelo menos uma das deficiências investigadas, o que corresponde a cerca de 24\% da população brasileira (IBGE, 2010a).

Importante frisar que o Censo de 2010 abordou a evolução do conceito de deficiência, pois considerou não apenas o modelo biomédico (patologias, sintomas e enquadramentos da área da saúde), considerando também a limitação conforme os fatores socioambientais (IBGE, 2010a), diferentemente do recenseamento anterior, realizado no ano de 2000. O Censo de 2010, considerando a população brasileira residente por situação de domicílio, apontou que o número da população urbana atingiu cerca de 161 milhões de pessoas, enquanto o número da população rural alcançou menos de 30 milhões (IBGE, 2010b). Evidenciou-se, portanto, especialmente nas últimas décadas do século XX, um número expressivo de êxodo rural, invertendo-se o panorama registrado até pouco mais da primeira metade do referido século.

Quanto aos indicadores demográficos referentes à urbanização, verificou-se no Brasil em 2010 uma taxa de urbanização no patamar de 84,36\%, com taxa média geométrica de crescimento anual de $1,17 \%$, densidade demográfica de 22,43 hab./km² (habitantes por quilômetro quadrado). Os dados obtidos com o censo de 2010 foram objeto de estudo compilado realizado pelo IBGE no ano de 2020, com projeções pautadas nos números então recenseados. Tendo-se, em 2010, apurado que a população brasileira era de 190.755.799 pessoas, sendo 160.925 .804 no meio urbano e 29.829 .995 no meio rural, a projeção para o ano de 2020 foi de 211.755.692 pessoas (IBGE, 2020). 
A partir de tais estatísticas, despontaram no Brasil pesquisas destinadas a apurar as condições das cidades para abrigar o número expressivo de pessoas decorrente da urbanização. Nesse contexto, merece destaque no presente estudo a compilação realizada pelo Observatório das Metrópoles ${ }^{14}$, instituto que passou a calcular o Índice de Bem-estar Urbano (IBEU) a partir dos dados censitários do IBGE. Para tanto, utilizam-se indicadores que verificam cinco dimensões: mobilidade urbana, condições ambientais urbanas, condições habitacionais urbanas, atendimento de serviços coletivos urbanos e infraestrutura urbana.

Segundo a compilação realizada pelo Observatório (2018), as dimensões estudadas revelaram uma grande diversidade referente ao bem-estar urbano no Brasil. Apesar de apenas seis municípios apresentarem condições muito ruins de bem-estar urbano, somente 273 apresentarem condições muito boas, de um conjunto de 5.565 municípios do país. Esses 273 municípios que apresentam as melhores condições de bem-estar urbano correspondem a 4,9\% do total de municípios do Brasil. Em contraponto, na parte inferior, há 1.068 municípios com condições ruins de bem-estar urbano, correspondentes a 19,2\%. Em condições médias de bem-estar urbano, há 2.298 municípios, correspondentes a 41,3\%. E, em condições boas de bem-estar urbano, há 1.920 municípios, correspondentes a 34,5\% (OBSERVATÓRIO, 2018).

Das dimensões analisadas pelo Observatório das Metrópoles, duas, em especial, relacionam-se com o bem-estar urbano das pessoas com deficiência: a mobilidade e a infraestrutura. Isso porque a dimensão da mobilidade urbana é construída a partir do tempo de deslocamento diário de casa para o trabalho. Já a dimensão de infraestrutura urbana compreende iluminação pública, pavimentação, calçada, meio-fio/guia, bueiro ou boca de lobo, rampa para cadeirantes e logradouros, indicadores que demonstram as condições de infraestrutura na cidade que podem possibilitar (quando da sua existência) melhor qualidade de vida para pessoas, estando relacionados com a acessibilidade, saúde e outras dimensões do bem-estar urbano diretamente relacionadas às pessoas com deficiência.

No que tange à dimensão de mobilidade do IBEU, verifica-se grande parte dos municípios brasileiros em condições boas e muito boas, correspondentes a $12,1 \%$ e $84,7 \%$, respectivamente, o que totaliza 5.388 municípios do país. Dos outros 177 municípios, 103

\footnotetext{
${ }^{14}$ O Observatório das Metrópoles integra o Instituto Nacional de Ciência e Tecnologia (INCT) do CNPq com o programa de pesquisa "As Metrópoles e o Direito à Cidade na inflexão da ordem urbana brasileira". Trata-se de um instituto que "trabalha de forma sistemática e articulada sobre os desafios metropolitanos colocados ao desenvolvimento nacional", apresentando como referência "a compreensão das mudanças das relações entre sociedade, economia, Estado e os territórios conformados pelas grandes aglomerações urbanas brasileiras" (OBSERVATÓRIO, 2020).
} 
apresentam condições médias de mobilidade, 61 apresentam condições ruins e 13, condições muito ruins (OBSERVATÓRIO, 2018).

Quanto à infraestrutura urbana, os números referem tratar-se não apenas de um problema de dimensões nacionais, mas, principalmente, de um problema metropolitano. Isso porque, dos 294 municípios das principais regiões metropolitanas do país, 132 estão em nível ruim e 111 municípios estão em nível muito ruim de bem-estar urbano, correspondendo a 82,6\% dos municípios metropolitanos. Além disso, 48 municípios estão em nível médio de bem-estar urbano. Ou seja, no Brasil, um país com dimensões continentais, somente três municípios apresentam boa condição de bem-estar urbano referente à infraestrutura (OBSERVATÓRIO, 2018).

Os dados relativos ao IBEU quanto às dimensões da mobilidade e da infraestrutura urbana mostram-se adequados para analisar as condições das pessoas com deficiência porquanto são setores dos mais afetados pelo crescimento das cidades, considerando-se que o desenvolvimento econômico acompanha tal crescimento e interfere nos fatos socioambientais. Vinci (2020, p. 179), nesse sentido, esclarece que tais afetações foram maiores "nos últimos 10-15 anos", referindo-se ao período que compreende as duas primeiras décadas do século XXI. ${ }^{15}$

No que concerne à efetividade de direitos e sua relação com o IBEU, especificamente em suas dimensões da mobilidade e da infraestrutura urbana, devem ser consideradas as deficiências com base na categorização a elas conferida pelo ordenamento jurídico brasileiro. O art. 5, I, do Decreto n. 5.296/2004 conceitua pessoa com deficiência como sendo aquela que possui limitação ou incapacidade para o desempenho de atividade e se enquadra nas seguintes categorias: (a) deficiência física; (b) deficiência auditiva; (c) deficiência visual; (d) deficiência mental; e (e) deficiência múltipla - associação de duas ou mais deficiências (BRASIL, 2004). Ainda, a partir da Lei n. 12.764/2012, as pessoas com transtorno do espectro autista (TEA) passaram a ser consideradas pessoas com deficiência, por apresentarem deficiência significativa na comunicação e na interação social (BRASIL, 2012).

A referida categorização convive harmoniosamente com o conceito de deficiência que se encontra em evolução no Brasil, buscando adequar-se com o que preceitua a

\footnotetext{
${ }^{15}$ Segundo o autor: "Le città sono state storicamente un spazio privilegiato per diverse forme di condivisione di beni e servizi, dalle biblioteche pubbliche ai servizi di comunità, ma è solo negli ultimi 10-15 anni che tali pratiche hanno interessato in forma sistematica il settore dei trasporti e la mobilità" (VINCI, 2020, p. 179).
} 
Convenção Internacional sobre os Direitos das Pessoas com Deficiência e seu Protocolo Facultativo. Nesse caminho evolutivo, considera-se, então, acertado adotar a visão conceitual com aporte contemporâneo, coadunada com os dizeres da Convenção, para o fim de considerar o conceito de deficiência que reconhece o impedimento das pessoas no convívio social em detrimento de critérios biológicos (BRASIL, 2009). Evidencia-se, dessa forma, cada vez mais a importância dos elementos ambientais urbanos na categorização das deficiências e a influência de uma cidade sustentável para o exercício de direitos e o pleno desenvolvimento das pessoas com deficiência.

\section{CONCLUSÃO}

A presente pesquisa buscou elucidar, a partir das noções teóricas e de dados previamente produzidos, se os índices apontados como determinantes para aferir o bem-estar urbano podem servir, igualmente, como balizadores para a constatação de maior ou menor efetividade de direitos para as pessoas com deficiência, especialmente os direitos sociais. Para tanto, tomou-se a concepção de pessoas com deficiência como sendo não aquelas que possuem alguma restrição exclusivamente biológica, como, por exemplo, a falta de um membro ou função organicamente considerados, mas, sim, aquelas com restrição de participação do meio em que vivem, em virtude de eventuais limitações, a partir do que preceitua a Convenção Internacional sobre os Direitos das Pessoas com Deficiência e seu Protocolo Facultativo.

O fenômeno determinante para a identificação e resolução do problema de pesquisa, portanto, foi a deficiência pela desigualdade, constituindo-se como critérios balizadores os impedimentos advindos de fatores socioambientais. Considerou-se, ainda, a definição legal brasileira para categorização das deficiências, segundo a qual são considerados, em diversos graus, impedimentos de ordem física, visual, mental e múltipla (quando se associam duas ou mais das referidas deficiências).

No que tange ao direito à cidade, tomou-se sua concepção como sendo um espaço social que necessita acompanhar os fatos sociais, de forma sustentável. Considerando-se, assim, a cidade como uma arena de convívio, a falta de inserção e interação no meio urbano relaciona-se diretamente com as deficiências quando a ausência de políticas públicas adequadas cause restrições às pessoas. Daí a intersecção do bem-estar urbano com a efetivação de direitos (nomeadamente, os direitos sociais), já que as pessoas com deficiência 
não podem ser coibidas, por exemplo, de ter acesso a prédios públicos, à moradia digna ou a quaisquer outros elementos constituintes da vida urbana sustentável.

Nesse contexto, os dados analisados na presente pesquisa evidenciaram uma predominância de condições médias e boas de bem-estar nas cidades, consideradas globalmente a partir da análise das seguintes dimensões urbanas: mobilidade, condições ambientais, condições habitacionais, atendimento de serviços coletivos e infraestrutura. Pequeno número de locais no país apresentaram as condições gerais de bem-estar urbano muito ruins, predominando, conforme referido, índices médios e bons.

Quanto às dimensões de mobilidade e infraestrutura urbana analisadas especificamente, pois consideradas determinantes para apurar o bem-estar das pessoas com deficiência, os índices revelaram-se distintos. Enquanto, por um lado, predominaram condições muito boas de mobilidade urbana em $84,7 \%$ dos municípios brasileiros, de outro norte foram revelados graves problemas de infraestrutura, especialmente nos espaços das metrópoles. Considerando-se que, quanto à infraestrutura, $82,6 \%$ dos municípios metropolitanos apresentaram índices ruins e muito ruins, a falta de estrutura adequada nos espaços citadinos revelou-se um problema urbano por excelência.

Evidenciou-se, dessa forma, que não existem significativas dificuldades de deslocamento na maioria dos núcleos urbanos brasileiros, cumprindo-se a mobilidade proposta como uma das dimensões de bem-estar nas cidades. Isso facilita o "ir e vir" das pessoas com deficiência, possibilitando-lhes o desenvolvimento pessoal e direito de muitas atividades e, por consequência, o exercício de direitos. No que concerne à dimensão da infraestrutura, porém, não se pode afirmar o mesmo, porquanto foram apontados óbices na prestação de adequadas condições urbanas relacionadas a pavimentação, calçada, meiofio/guia, bueiro ou boca de lobo, iluminação pública, rampa para cadeirantes e logradouros.

Com isso, alguns direitos sociais podem não estar sendo prestados de forma efetiva às pessoas com deficiência, já que, se o cidadão não possui acesso a determinados locais urbanos por não existir rampa de acesso, iluminação pública ou pavimentação, poderá ter cerceamento em direitos considerados fundamentais, tais como moradia digna, lazer, segurança, saúde, dentre outros. E mais: considerando-se o modelo social para aferição das deficiências, fundado na Convenção sobre os Direitos das Pessoas com Deficiência da Organização das Nações Unidas, muitas pessoas que não possuem perda de membro ou função, por exemplo, poderão ser consideradas deficientes. Dessa forma, a questão ultrapassa 
a previsão normativa, uma vez que a efetivação dos direitos sociais para as pessoas com deficiência exige a prestação de condições físicas e sociais aptas a propiciar o exercício de direitos.

Concluiu-se, assim, a partir da análise específica das dimensões de mobilidade e infraestrutura, que os índices de bem-estar urbano são determinantes para o exercício de direitos pelas pessoas com deficiência. Aliados à noção de cidade sustentável, os apontadores relacionados ao bem-estar urbano revelaram-se imprescindíveis para definir se as pessoas com deficiência estão exercendo, ou não, em condições plenas, os direitos fundamentais no ambiente citadino, especialmente no que tange à prestação e efetividade dos direitos sociais.

\section{REFERÊNCIAS}

ALEXY, Robert. Teoria dos direitos fundamentais. Trad. Virgílio Afonso da Silva. $2^{\mathrm{a}}$ ed., $4^{\mathrm{a}}$ tir. São Paulo: Malheiros, 2015.

ALVINO-BORBA, Andreilcy; MATA-LIMA, Herlander. Exclusão e inclusão social nas sociedades modernas: um olhar sobre a situação em Portugal e na União Europeia. Revista Serviço Social \& Sociedade, São Paulo, n. 106, p. 219-240, abr./jun. 2011.

BOSSELMANN, Klaus. The principle of sustainability: transforming law and governance. Hampshire: Ashgate, 2008.

BOSSELMANN, Klauss. O princípio da sustentabilidade. Trad. Phillip Gil França. São Paulo: RT, 2015.

BRASIL. [Constituição (1988)]. Constituição da República Federativa do Brasil de 1988. Brasília, DF: Presidência da República, [2020]. Disponível em:

http://www.planalto.gov.br/ccivil_03/constituicao/constituicao.htm. Acesso em 5 set.2020.

BRASIL. Decreto n. 5.296, de 2 de dezembro de 2004. Regulamenta as Leis n. 10.048, de 8 de novembro de 2000, que dá prioridade de atendimento às pessoas que especifica, e 10.098, de 19 de dezembro de 2000, que estabelece normas gerais e critérios básicos para a promoção da acessibilidade das pessoas portadoras de deficiência ou com mobilidade reduzida, e dá outras providências. Diário Oficial da União: Brasília, DF, 3 dez. 2004. Disponível em: http://www.planalto.gov.br/ccivil_03/_Ato2004-2006/2004/Decreto/D5296.htm. Acesso em: 2 ago.2020.

BRASIL. Decreto n. 6.949, de 25 de agosto de 2009. Promulga a Convenção Internacional sobre os Direitos das Pessoas com Deficiência e seu Protocolo Facultativo, assinados em Nova York, em 30 de março de 2007. Diário Oficial da União: Brasília, DF, 26 ago.2009. Disponível em: http://www.planalto.gov.br/ccivil_03/_ato2007-

2010/2009/decreto/d6949.htm. Acesso em: 2 ago. 2020. 
BRASIL. Lei n. 12.764, de 27 de dezembro 2012. Institui a Política Nacional de Proteção dos Direitos da Pessoa com Transtorno do Espectro Autista; e altera o $§ 3^{\circ}$ do art. 98 da Lei $n$. 8.112, de 11 de dezembro de 1990. Diário Oficial da União: Brasília, DF, 28 dez.2012. Disponível em: http://www.planalto.gov.br/ccivil_03/_ato2011-2014/2012/lei/112764.htm. Acesso em: 2 ago. 2020.

BUCCI, Maria Paula Dallari. Políticas públicas e direito administrativo. Revista de Informação Legislativa. Brasília, v. 34, n. 133, p. 89-98, jan./mar. 1997. Disponível em: http://www2.senado.leg.br/bdsf/item/id/198. Acesso em: 05.ago.2015.

FREITAS, Juarez. O controle dos atos administrativos e os princípios fundamentais. $4^{\text {a }}$ ed. São Paulo: Malheiros, 2009.

FREITAS, Juarez. Sustentabilidade: direito ao futuro. 2ª ed. Belo Horizonte: Fórum, 2012.

FREITAS, Juarez; GARCIA, Júlio César. Evolução conceitual do princípio da sustentabilidade. Revista Direito Sem Fronteiras - Universidade Estadual do Oeste do Paraná. Foz do Iguaçu. Jan/Jun. 2018; v. 2 (4); p. 13-26.

HÄBERLE, Peter. A dignidade humana como fundamento da comunidade estatal. In: SARLET, Ingo Wolfgang (Org.). Dimensões da dignidade: ensaios de filosofia do direito e direito constitucional. 2. ed, rev. et ampl. Porto Alegre: Livraria do Advogado, 2009, pp. 45103.

HARVEY, David. Direito à cidade. Trad. Jair Pinheiro. Lutas Sociais, São Paulo, n.29, p.7389, jul./dez. 2012.

HARVEY, David. Cidades rebeldes: do direito à cidade à revolução urbana. Trad. Jeferson Camargo. São Paulo: Martins Fontes, 2014.

IBGE - Instituto Brasileiro de Geografia e Estatística. Censo demográfico: características gerais da população, religião e pessoas com deficiência, 2010a. Disponível em: http://biblioteca.ibge.gov.br/visualizacao/periodicos/94/cd_2010_religiao_deficiencia.pdf. Acesso em: 30 jul.2020.

IBGE - Instituto Brasileiro de Geografia e Estatística. Censo demográfico: população residente por situação de domicílio, 2010b. Disponível em:

https://www.ibge.gov.br/estatisticas/sociais/populacao/2098-np-censo-demografico/9662censo-demografico-2010.html. Acesso em: 6 set.2020.

IBGE - Instituto Brasileiro de Geografia e Estatística. Brasil em Números: Brazil in Figures. Rio de Janeiro, v. 28, p. 1-498, 2020. Disponível em:

https://biblioteca.ibge.gov.br/visualizacao/periodicos/2/bn_2020_v28.pdf. Acesso em: 23 set.2020.

LEFEBVRE, Henri. O direito à cidade. Trad. Rubens Eduardo Frias. São Paulo: Centauro, 2001. 
MEDEIROS, Jeison Francisco de. Tributação verde: um importante instrumento à efetivação do desenvolvimento sustentável no âmbito das cidades. In: DE MARCO, Cristhian Magnus (org.). $\mathbf{O}$ futuro das cidades: direitos fundamentais, sustentabilidade, resiliência e disrupção. Joaçaba: Unoesc, 2020. Disponível em:

https://www.unoesc.edu.br/images/uploads/editora/o_futuro_das_cidades.pdf. Acesso em: 6 set. 2020.

NUSSBAUM, Martha. Fronteiras da Justiça: deficiência, nacionalidade, pertencimento à espécie. Trad. Susana de Castro. São Paulo: WMF Martins Fontes, 2013.

OBSERVATÓRIO das Metrópoles. IBEU Municipal: índice de bem-estar urbano dos municípios brasileiros. Rio de Janeiro, Observatório das Metrópoles, 2018. Disponível em: https://www.observatoriodasmetropoles.net.br/wp-content/uploads/2019/11/IBEU-

MUNICIPAL_FINAL.pdf. Acesso em: 6 set.2020

OBSERVATÓRIO das Metrópoles. Apresentação. Rio de Janeiro, Observatório das Metrópoles, 2020. Disponível em: https://www.observatoriodasmetropoles.net.br/. Acesso em: 6 set.2020.

ROLNIK, Raquel; KLINK, Jeroen. Crescimento econômico e desenvolvimento urbano: por que nossas cidades continuam tão precárias? Novos estudos, São Paulo, n. 89, p. 89-109, ed. 89, v. 30, n. 1, mar. 2011. Disponível em: http://novosestudos.uol.com.br/produto/edicao89/. Acesso em: 6 set.2020.

ROUSSEAU, Jean-Jacques. Do contrato social. Trad. Rolando Roque da Silva. Edição eletrônica: Ridendo Castigat Mores, 2001. Disponível em:

http://www.ebooksbrasil.org/adobeebook/contratosocial.pdf. Acesso em: 13.set.2015.

SARLET, Ingo Wolfgang. A eficácia dos direitos fundamentais: uma teoria geral dos direitos fundamentais na perspectiva constitucional. Porto Alegre: Livraria do Advogado, 2012.

SASSAKI, Romeu Kazumi. Inclusão: construindo uma sociedade para todos. $8^{\mathrm{a}} \mathrm{ed}$. Rio de Janeiro: WVA, 2010.

VINCI, Ignazio. Mobilità condivisa e processi di sviluppo sostenibile nelle città: le questioni aperte e gli spazi per le politiche pubbliche. Diritto \& Questioni Pubbliche: Rivista di Filosofia del Diritto e Cultura Giuridica, v. 20, n. Special Issue, jun/2020, p. 173-186. HeinOnline. Disponível em:

https://heinonline.org/HOL/Contents?handle=hein.journals/dirquesp20\&id=1\&size=2\&index $=\&$ collection=journals. Acesso em: 6 set.2020. 